Phác đồ chứa TS-1 là một lưa chọ hợp lý cho bệnh nhân ung thư dạ dày giai đoạn muộn.

\section{TÀI LIÊU THAM KHẢO}

1. Bô Y tế (2020). Hướng dẫn chẩn đoán và điều trị bệnh ung thư dạ dày.

2. GLOBOCAN Cancer fact sheets: stomach (2020). https://gco.iarc.fr/today/data/factsheets/cancers/7 -Stomach-fact-sheet.pdf

3. Koizumi W, Narahara $\mathbf{H}$, Hara $\mathbf{T}$, Takagane A, Akiya T, Takagi M, et al (2008). TS-1 plus cisplatin versusTS-1 alone for first-line treatment of advanced gastric cancer (SPIRITS trial): A phase III trial. Lancet Oncol, 9, 215-21.

4. Nguyến Minh Phương (2020). Đánh giá kết quả phác đồ TS-1 - Cispaltin trong điều trị bước một ung thư da dày giai đoạn muộn tại bệnh viện $K$. Trường Đại học Y Hà Nội.

5. Ter Veer, E. et al. The efficacy and safety of S-1based regimens in the first-line treatment of advanced gastric cancer: a systematic review and meta-analysis. Gastric Cancer 19, 696-712 (2016).

\title{
KẾT QUẢ ĐIỀU TRI BIẾN CHỨNG DO XẠ TRỊ UNG THƯ CỔ TỬ CUNG
}

\section{TÓM TẮT}

Mục Đích: Đánh giá kết quả điều trị biến chứng do xạ trị ung thư cổ tứ cung. Phương pháp: Nghiên cứu hiồi cứu trên 37 bệnh nhân được chẩn đoán biến chứng tiêu hóa, sinh dục, tiết niệu do xa trị ung thư cổ tử cung được phẫu thuật tại bệnh viện Việt Đức từ 2/2007 đến 12/2020. Kết quả: $100 \%$ BN có loét trực tràng chảy máu, trong đó 18 bệnh nhân $(48,6 \%)$ có biến chứng hẹp và rò vào tạng sinh dục, tiết niệu. Một số biến chứng về sinh dục tiết niệu khác: viêm bàng quang 8 BN $(21,6 \%)$, hẹp niệu quản 8 BN $(21,6 \%)$, hẹp âm đạo (không rò vào trực tràng) $26 \mathrm{BN}(70,3 \%)$. Chỉ đinh mổ chủ yếu do viêm loét trực tràng chảy máu 19/37 bệnh nhân (51,4\%). Phẫu thuật cắt loại trừ thương tổn (PT Mille và Hartmann) là chủ yếu $27 \mathrm{BN}$, chiếm tỉ lệ 73\%. Cắt trực tràng, tứ cung, BQ, nối ĐTÔHM + HMNT 6/37 bệnh nhân (16,2\%). Khống có tai biến, biến chứng nặng sau mổ, không có tử vong. Kết quả lâu dài, 7 bệnh nhân đã chết do ung thư tái phát tại chỗ, hoặc u di căn, chiếm tỷ lệ 19\%. Các bệnh nhân sau mổ khỏe mạnh, tham gia sinh hoạt cộng đồng tương đối bình thường, không còn chảy máu tiêu hóa. Kết luận: xạ trị ung thư cổ tử cung còn có những biến chứng nặng nề cho các tạng và cấu trúc giải phẫu lân cận. Kết quả phẫu thuật tốt, không có tai biến, biến chứng nặng sau mồ. Kết quả lâu dài, nguyên nhân tử vong do ung thư tái phát, di căn.

Tư Khóa: Viêm loét trực tràng chảy máu, rò trực tràng âm đạo.

\section{SUMMARY}

\section{RESULTS OF TREATMENT COMPLICATIONS} RADIATION-INDUCED CERVICAL CANCER

Objective: Evaluation the results of treatment for complications caused by radiation therapy for cervical cancer. Methods: Retrospective study on 37 patients

\section{${ }^{1}$ Bệnh viện $K$ \\ ${ }^{2}$ Trung tâm hậu môn trực tràng Bệnh viện Việt Đức Chịu trách nhiệm chính: Nguyễn Đức Duy \\ Email: ducduy272@gmail.com \\ Ngày nhận bài: 23.6.2021}

Ngày phản biên khoa họ: 17.8.2021

Ngày duyệt bài: 25.8.2021

\section{Nguyễn Đức Duy ${ }^{1}$, Nguyễn Xuân Hùng ${ }^{2}$}

diagnosed with gastrointestinal, genitourinary complications caused by radiation therapy for cervical cancer who were operated at Viet Duc hospital from $2 / 2007$ to $12 / 2020$. Results: $100 \%$ of patients had bleeding rectal ulcer, of which 18 patients (48.6\%) had complications of stenosis and genitourinary organs fistula. Some other genitourinary complications: cystitis 8 patients $(21.6 \%)$, ureteral stenosis 8 patients $(21.6 \%)$, vaginal stenosis (no fistula into the rectum) 26 patients $(70.3 \%)$. Indication for surgery mainly due to bleeding rectal ulcers $19 / 37$ patients $(51.4 \%)$. Surgical removal of the lesion (Mille and Hartmann procedures) is the mainly for 27 patients, accounting for $73 \%$. Proctectomy, hysterectomy, cystectomy, coloanal anastomosis and colostomy for $6 / 37$ patients $(16,2 \%)$. There was no complications, severe complications postoperative, and there was no deaths. Long-term results, 7 patients died from local recurrence, or metastasis, accounting for $19 \%$. The postoperative patients are healthy, participate in community activities relatively normally, no longer have gastrointestinal bleeding. Conclusion: Radiation therapy for cervical cancer still has severe complications for adjacent organs and anatomical structures. Surgery brought good results, there was no complications and serious complications after surgery. Long-term results, the cause of death is cancer recurrence and metastasis. fistula.

Keywords; rectal ulcer bleeding, rectovaginal

\section{I. ĐĂT VẤN ĐỀ}

Ung thư ổ tử cung là môt trong những ung thư hay gặp ở nữ giới. Điều trị ung thư cổ tử cung dựa vào giai đoạn của bệnh. Ớ Việt Nam, điều trị ung thư cổ tử cung chủ yếu là xạ trị kết hợp với phẫu thuật, do bệnh thường phát hiện giai đoạn muộn. Tia xạ có khả năng tiêu diệt tế bao ung thư, nhưng tia xạ cũng gây ra những tổn thương các tổ chức, tạng lân cận. Các biến chứng thường gặp như: viêm loét trực tràng chảy máu, rò trực tràng âm đạo, hẹp hậu môn, viêm rò bàng quang...

Điều trị các biến chứng do xạ trị ung thư cổ 
tử cung rất khó khăn do các tổn thương từ tia xạ thường rộng, tổ chức khó liền sẹo, tồn tại một số di chứng khó hồi phục. Nghiên cứu thực hiện với hai mục tiêu:

- Mô tả đặc điểm thương tổn các biến chứng do tia xạ ung thư cổ tử cung.

- Đánh giá kêt quả phẫu thuật các biến do xạ trị ung thư cổ tử cung.

\section{II. ĐỐI TƯợNG VÀ PHƯƠ'NG PHÁP NGHIÊN CỨU}

- Các bệnh nhân được chẩn đoán biến chứng tiêu hóa, sinh dục, tiết niệu do xạ trị ung thư cổ tử cung được phẫu thuật tại bệnh viện Việt Đức từ 2/2007 đến $12 / 2020$.

- Loại trừ các bệnh nhân viêm loét đại trực tràng không do xạ trị ung thư cổ tử cung, bệnh nhân có kết quả giải phẫu bệnh ung thư ở trực tràng.

- Phương pháp nghiên cứu mô tả hồi cứu, lấy mẫu toàn bộ.

\section{KẾT QUẢ NGHIÊN CỨU}

1. Tuổi:

\begin{tabular}{|c|c|c|}
\hline Nhóm tuối & $\mathbf{n}$ & $\mathbf{\%}$ \\
\hline$<40$ & 1 & 2,7 \\
\hline $40-59$ & 24 & 64,9 \\
\hline $60-69$ & 12 & 32,4 \\
\hline$\geq 70$ & 0 & 0 \\
\hline Tống & $\mathbf{3 7}$ & $\mathbf{1 0 0}$ \\
\hline
\end{tabular}

Độ tuối phẫu thuật tập trung 40 - 59 tuối, chiếm $64,9 \%$

\section{Thương tổn:}

\begin{tabular}{|c|c|c|}
\hline Các tốn thương & $\mathbf{n}$ & $\mathbf{( \% )}$ \\
\hline $\begin{array}{c}\text { Loét trực tràng chảy máu nặng, } \\
\text { tái phát }\end{array}$ & 19 & 51,4 \\
\hline Loét, hẹp trực tràng & 2 & 5,4 \\
\hline Loét, rò trực tràng - âm đạo & 12 & 32,4 \\
\hline Loét, rò trực tràng - bàng quang & 2 & 5,4 \\
\hline $\begin{array}{c}\text { Loét, rò trực tràng - âm đạo - } \\
\text { băng quang }\end{array}$ & 2 & 5,4 \\
\hline Tống & $\mathbf{3 7}$ & $\mathbf{1 0 0}$ \\
\hline
\end{tabular}

- 100\% BN có loét trực tràng chảy máu, trong đó 18 bệnh nhân $(48,6 \%)$ có biến chứng hẹp và rò vào tạng sinh dục, tiết niệu.

- Một số biến chứng về sinh dục tiết niệu khác: viêm bàng quang $8 \mathrm{BN}(21,6 \%)$, hẹp niệu quản $8 \mathrm{BN}(21,6 \%)$, hẹp âm đạo (không rò vào trực tràng) $26 \mathrm{BN}(70,3 \%)$

\section{Phương pháp phẫu thuật:}

\begin{tabular}{|c|c|c|}
\hline Phâu thuật & $\mathbf{n}$ & $\mathbf{\%}$ \\
\hline Mille & 18 & 48,6 \\
\hline Hartmann & 9 & 24,4 \\
\hline Đóng rò trực tràng âm đạo+HMNT & 2 & 5,4 \\
\hline $\begin{array}{c}\text { Cắt trực tràng, tử cung, BQ, nối ĐT- } \\
\text { ÔHM + HMNT }\end{array}$ & 6 & 16,2 \\
\hline HMNT & 1 & 2,7 \\
\hline
\end{tabular}

\begin{tabular}{|c|c|c|}
\hline $\begin{array}{c}\text { Nong hậu môn-trực tràng+ khâu } \\
\text { cầm máu }\end{array}$ & 1 & 2,7 \\
\hline Tống & $\mathbf{3 7}$ & $\mathbf{1 0 0}$ \\
\hline
\end{tabular}

Phẫu thuật cắt loại trừ thương tổn (PT Mille và Hartmann) là chủ yếu $27 \mathrm{BN}$, chiếm tỉ lệ $73 \%$.

\section{Kết quả sớm sau mổ}

Nhiễm trùng vết mổ: 4 BN $(10,8 \%)$

- Rò nước tiểu trực tràng (nhóm 6 bệnh nhân, mổ cắt trực tràng, âm đạo, đóng rò bàng quang) $1 \mathrm{BN}(16,6 \%)$.

Đại tiện máu: 3 BN $(8,1 \%)$.

Không có biến chứng nặng sau mổ, không có tử vong.

\section{Kết quả xa sau mổ}

Theo dõi sau phẫu thuật 37 bệnh nhân, 7 bệnh nhân đã chết do ung thư tái phát tại chỗ, hoặc u di căn, chiếm tỷ lệ $19 \%$.

Các bệnh nhân còn lại được phẫu thuật loại trừ thương tổn (PT Mille và Hartmann hoặc đã đóng HMNT bảo vệ) sống khỏe mạnh, tham gia sinh hoạt cộng đồng tương đối bình thường, không còn chảy máu tiêu hóa.

\section{BÀN LUÂ̂N}

Ung thư ổ tử cung là một trong những ung thư hay gặp ở nữ giới. Điều trị ung thư cổ tử cung dựa vào giai đoạn của bệnh. Ở Việt Nam, do bệnh thường phát hiện giai đoạn muộn, điều trị chủ yếu là xạ trị kết hợp với phẫu thuật $[1,2]$. Tia xạ có khả năng tiêu diệt tế bao ung thư, nhưng tia xạ cũng gây ra những tổn thương các tổ chức, tạng lân cận. Các biến chứng thường gặp như: viêm loét trực tràng chảy máu, rò trực tràng âm đạo, hẹp hậu môn, viêm rò bàng quang...[4,5,6]. Điều trị các biến chứng do xạ trị ung thư cố tử cung rất khó khăn do các tổn thương từ tia xạ thường rộng, tổ chức khó liền sẹo, tồn tại một số di chứng khó hồi phục.

Kết quả nghiên cứu của chúng tôi cho thây, về đặc điểm thương tổn, $100 \%$ bệnh nhân bị viêm loét trực tràng chảy máu, đã được chẩn đoán và điều trị nhiêu năm. Nhiêu bệnh nhân đến trong tình trạng suy kiệt, thiếu máu, đau đớn kéo dài, ảnh hưởng đến tâm sinh lý. Các nghiên cứu của Nguyễn Xuân Hùng, Nguyễn Văn Tuyên cũng cho thây tình trạng tương tự $[1,2]$. Do tia xạ điều trị ung thư, các tạng lân cận như âm đạo, hệ tiết niệu cũng bị phá hủy nghiêm trọng. Thống kê cho thấy 12/37 bệnh nhân $(32,4 \%)$ bị rò trực tràng - âm đạo. Tỉ lệ viêm bàng quang, hẹp niệu đạo $8 / 37$ (21,6\%). Trong đó có 4 bệnh nhân có rò trực tràng bàng quang. Các thương tổn này ảnh hưởng nhiều tới đời sống sinh hoạt, tâm sinh lý và suy giảm chức 
năng các tạng. Thương tổn lan rộng, kéo dài, khó hồi phục, đặt ra một thách thức lớn cho việc điều trị. Các nghiên cứu khác cũng chỉ ra các vấn đề tương tự $[1,4,6]$.

Về điêu trị, kết quả ghi nhận 27/37 (73\%) bệnh nhân phải thực hiện phẫu thuật cắt cụt trực tràng hay phẫu thuật Hartmann. Có 6 bệnh nhẩn $(16,2 \%)$ phải chịu phẫu thuật cả 3 tạng trực tràng, bàng quang, tử cung và phải mang hậu môn nhân tạo tạm thời hoặc vĩnh viễn cho thấy xạ trị gây những hậu quả khá nghiêm trọng cho người bệnh.

Về phương diện phẫu thuật, đây là phẫu thuật đa tạng, tổ chức xơ sẹo, khó liền sẹo sau mổ, trên cơ địa người bệnh suy kiệt kéo dài, nên vấn đề đánh giá đầy đủ hệ thống phải được đăt ra và giải quyết triệt để. Bên cạnh việc chẩn đoán, giải quyết các biến chứng còn phải đánh giá tình trạng bệnh ung thư cổ tử cung. Kết quả nghiên cứu cho thấy 37 bệnh nhân tai thười điểm phẫu thuật không có ung thư tái phát, hâuu phẫu diễn biến thuận lợi, không có tai biến và biến chứng nặng sau mổ.

Kết quả lâu dài, 7 bệnh nhân (19\%), chết do ung thư tái phát, di căn. Các trường hợp còn sống, sinh hoạt và hòa nhập công việc xã hội tương đối tốt. Không còn triệu chứng chảy máu tiêu hóa. Chức năng hệ tiết niệu ổn định, hài lòng sau phẫu thuật. Nghiên cứu khác cũng cho kết quả tương tự $[1,2]$.

\section{KẾT LUẬN}

Xạ trị ung thư cổ tử cung còn có những biến chứng nặng nề cho các tạng và cấu trúc giải phẫu lân cận. Một số cần can thiệp phẫu thuật, chỉ định chủ yếu do viêm trực tràng chảy máu $(51,4 \%)$, rò phân vào âm đạo, bàng quang (43,2\%).

Kết quả phẫu thuật tốt, không có tai biến, biến chứng nặng sau mổ. Kết quả lâu dài, nguyên nhân tử vong do ung thư tái phát, di căn.

\section{TÀI LIÊU THAM KHẢO}

1. Nguyễn Xuân Hùng (2009) Kết quả điều trị rò trực tràng - âm đạo, tạp chí ngoại khoa số1; 4: tr. $26-29$.

2. Nguyển Văn Tuyên (2008) Nghiên cứu điều trị ung thư cổ tử cung giai đoạn IB-II bằng phương phảp phẫu thuật kết hợp với xạ trị", Luận án tiến sỹ y học, Trường Đại học Y Hà Nội, tr.133̇-134.

3. Small W Jr, Bacon MA, Bajaj A, et al (2017) Cervical cancer: a global health crisis. Cancer 123:2404-12

4. Yang, Jian PhDa; Cai, Haoyang PhDa; Xiao, Zhi-Xiong $\mathrm{PhD}^{\mathrm{a}}$; Wang, Hangyu $\mathrm{MD}^{\mathrm{b}_{*} ;}$; Yang, Ping MDc . (2019) Effect of radiotherapy on the survival of cervical cancer patients volum 98- issue - p e16421

5. Shi D, Liang Z, Zhang C, et al, (2018) The effect of surgery on the survival status of patients with locally advanced cervical cancer after radiotherapy/chemoradiotherapy: a meta-analysis. BMC Cancer ; 18:308.

6. Ghabuous Á et al. (2013) Time course of late rectal- and urinary bladder side effects after MRIguided adaptive brachytherapy for cervical cancer". 535-40 Boni A.

\section{MÔ TẢ HÀNH VI TỰ CHĂM SÓC CỦA NGƯỜI BỆNH SUY TIM DO TĂNG HUYẾT ÁP TẠI TRUNG TÂM TIM MACH BÊ̂NH VIÊ̂N ĐA KHOA TỈNH HẢI DƯƠNG} Bùi Thị Hậu*, Nguyễn Thị Lan Anh**,
Đồ Thị Thu Hiền*, Đàm Văn Đạt*

\section{TÓM TẮT}

Với muc tiêu mô tả hành vi tư chăm sóc của người bệnh suy tim do THA và tìm hiểu một số yếu tỗ liênn quan đến hành vi tư chăm sóc của người bệnh suy tim do THA tại Trung tâm Tim mạch Bệnh viện Đa khoa tỉnh Hải Dương từ tháng 08/2020 đển tháng 04 /2021. Qua nghiên cứu cắt ngang 121 người bệnh suy

\footnotetext{
*Trường đại học kỹ thuật Y tế Hải Dương.

**Trướng đai hoc Y Hà Nôi

Chịu trách nhiệm chính: Bùi Thị Hậu

Email: hauhmtu1991@gmail.com

Ngày nhận bài: 22.6.2021

Ngày phản biên khoa hoc: 17.8.2021

Ngày duyệt bài: 24.8.2021
}

tim do tăng huyết áp tại Trung tâm Tim mach Bênh viện Đa khoa tỉnh Hải Dương. Kết quả cho thấy: Người bệnh từ 60 tuổi trở lên chiếm tỷ lệ 91,7\%. Điểm trung bình đạt cao nhất ở chỉ số duy trì tự chăm sóc $(24,02 \pm 7,368)$, thấp nhất ở chỉ số tự tin tự chăm sóc $(16,22 \pm 5,108)$. Điểm kiến thức về bênh suy tim 6,39 $\pm 1,519$. Điểm kiến thức theo dõi huyết áp 11,42 $\pm 1,025$. Điểm hố trơ xã hôi $55,49 \pm 18,766$. Có mối tương quan thuận giữa điểm kiến thức suy tim, điểm kiến thức theo dõi huyết áp, điểm hỗ trơ xã hôi với quản lý tự chăm sóc, duy trì tự chăm sóc, tự tin tự chăm sóc (hêe số tương quan rho $>0,5, p<0,001$ ). Có sự khác biệt giữa nhóm nam giới và nữ giới về điểm hành vi tư chăm sóc bản thân với $p<0,001$. Điểm trung bình duy tự chăm sóc của 2 nhóm phân độ HA bình thường cao và độ I với nhóm phân độ HA độ II 